\title{
Fictions narratives en prose de l'âge baroque. Répertoire analytique, sous la direction de Frank Greiner
}

\section{Laura Rescia}

\section{Q OpenEdition}

1 Journals

\section{Edizione digitale}

URL: http://journals.openedition.org/studifrancesi/427

DOI: $10.4000 /$ studifrancesi.427

ISSN: 2421-5856

\section{Editore}

Rosenberg \& Sellier

\section{Edizione cartacea}

Data di pubblicazione: 1 aprile 2015

Paginazione: 140

ISSN: 0039-2944

\section{Notizia bibliografica digitale}

Laura Rescia, «Fictions narratives en prose de l'âge baroque. Répertoire analytique, sous la direction de

Frank Greiner », Studi Francesi [Online], 175 (LIX | I) | 2015, online dal 01 avril 2015, consultato il 18 septembre 2020. URL : http://journals.openedition.org/studifrancesi/427 ; DOI : https://doi.org/ 10.4000/studifrancesi.427

Questo documento è stato generato automaticamente il 18 settembre 2020.

\section{(c)}

Studi Francesi è distribuita con Licenza Creative Commons Attribuzione - Non commerciale - Non opere derivate 4.0 Internazionale. 


\title{
Fictions narratives en prose de l'âge baroque. Répertoire analytique, sous la direction de Frank Greiner
}

\author{
Laura Rescia
}

\section{NOTIZIA}

Fictions narratives en prose de l'âge baroque. Répertoire analytique, Deuxième partie

(1611-1623), sous la direction de Frank GREINER, Paris, Classiques Garnier, 2014, pp. 1403.

1 Dopo un primo volume, apparso nel 2007 e dedicato al periodo compreso tra il 1585 e il 1610 , vede ora la luce il secondo della serie che si prefigge di completare l'indagine spingendosi fino al 1643. Il lavoro, che permette agli studiosi di avvalersi di uno strumento pregevole e di indubbia utilità, è, come noto, coordinato da F. Greiner, affiancato da un gruppo di specialisti del romanzo e della narrativa francese secentesca. L'impresa di Greiner poggia sul lavoro pioneristico di Maurice Lever, risalente al $1976 \mathrm{e}$ - ricordiamolo - relativo all'intero secolo; ma, a differenza del suo predecessore, Greiner si spinge ben oltre la già meritevole catalogazione di un insieme di testi poco noti, poiché l'analisi del corpus è estremamente dettagliata, affrontando problemi di categorizzazione di non semplice soluzione. Primo fra tutti, il tentativo di definizione del "genere" dell'opera repertoriata: una lunga lista di simboli è stata elaborata per dar conto, accanto al titolo, di differenti caratteristiche dell'opera, che si riferiscono alla forma, ma altresì alla tematica e alla funzione; ogni voce (e in questo volume se ne contano ben 195) comporta, a seguito del titolo, la descrizione materiale del testo, l'indicazione dell'esemplare consultato, osservazioni di carattere ecdotico e una dettagliatissima sinossi, suddivisa in sottoinsiemi riportanti il riferimento alle pagine del testo in cui ritrovare il passaggio riassunto. La mole e la complessità dell'intreccio del romanzo secentesco sono note, e rendono perciò utilissima un'impostazione analitica per chi voglia avvalersi di questo strumento per ulteriori indagini, sia sulle singole opere che trasversali. Tenendo fede ai principi già individuati per il primo 
volume, in considerazione della flessibilità del rapporto tra finzione e realtà nelle narrazioni del periodo considerato, si sono individuati, oltre ad un nucleo di romanzi e novelle propriamente dette, una nutrita schiera di opere ibride (canards, eroidi, compilazioni erudite, agiografie romanzate, racconti allegorici, fantasie galanti, dialoghi, traduzioni di epopee in prosa, racconti storici romanzati) che arricchiscono il panorama letterario di inizio secolo, di indubbia utilità per decifrare gli inserti epistolari, poetici, i discorsi proto-scientifici o religiosi, le allegorie e gli echi storicopolitici presenti nei romanzi e nelle novelle propriamente detti. Rispetto al repertorio di Lever, sono inoltre stati aggiunti un buon numero di titoli, mentre pochi sono stati gli emendamenti, riguardanti qualche correzione nelle attribuzioni e nelle datazioni. Il corpus di questo volume rispecchia un periodo di transizione tra due regni, la radicalizzazione di un certo cattolicesimo, con il conseguente moltiplicarsi di romanzi religiosi, e l'emergenza del libertinaggio, una cospicua narrativa epico-cavalleresca, nella quale gli influssi ispanici e italiani sono preponderanti, ma anche un nucleo di romanzi eroico-galanti, e come noto pastorali, la terza parte dell'Astrée (1619) rappresentando un momento apicale e influenzando un buon numero di narrazioni ricomprese nel periodo considerato. L'emergenza delle prime histoires comiques e delle histoires tragiques completa il quadro delle narrazioni maggiormente significative dell'epoca. Il repertorio è corredato da numerose appendici: tre articoli dedicati rispettivamente all'analisi delle traduzioni e adattamenti di opere spagnole (B. Mozo Marin e J. M. Losada Goya, pp. 1103-1124) di opere italiane (V. Castiglione Minischetti, pp. 1125-1137), e all'illustrazione della prosa narrativa (J.M. Chatelain, pp. 1139-1156); la classificazione del corpus in base al nome d'autore; un elenco analitico dei libri corredati da illustrazioni; una lista di testi introvabili o non compresi nel repertorio analizzato; la lista dei canards; alcuni frontespizi; l'indice dei nomi, dei titoli e - assai meritoriamente - un dettagliato indice tematico. 